\title{
1. COPD Pathogenesis from the Viewpoint of Risk Factors
}

\author{
Shinji Teramoto
}

\begin{abstract}
Chronic obstructive pulmonary disease (COPD) is characterized by irreversible airflow limitation in the lungs. Smoking is one of the amongst major risk factors for the development of COPD. Environmental pollution, age, and airway hyperreactivity are also the risk factors. The protease-antiprotease imbalance and the oxidant-antioxidant imbalance cause airway inflammation and destruction. The genes related to these balances may contribute to development of COPD pathology. Candidate gene-association studies and linkage analyses have been reported for COPD patients. The alpha-1 antitrypsin, glutathione S-transferase, microsomal epoxide hydrolase, and matrix metalloproteinase, are candidate genes. In acquired factors for COPD pathology, the adenoviral latent infection may enhance airway inflammation, leading to airflow obstruction. The current progress and future visions of genetic predisposition of COPD are discussed.
\end{abstract}

Key words: Smoking, protease-antiprotease imbalance, oxidant-antioxidant imbalance, Gene-Association Studies, adenoviral latent infection may

(DOI: 10.2169/internalmedicine.46.1775)

\section{Introduction}

Chronic obstructive pulmonary disease (COPD) is characterized by irreversible airflow limitation in the lungs. Although COPD was the 12th largest disease burden in the world in 1990, it is estimated that it will rise to be the fifth largest disease burden by 2020 (1-4). The most important risk factor for the development of COPD is smoking (Fig. 1). However, only 10-20\% of chronic heavy smokers develop symptomatic COPD, which indicates that a difference in susceptibility to tobacco smoke injury must exist and may be related to genetic factors (Fig. 2). Candidate gene-association studies and linkage analyses have been reported for COPD patients. We summarized the evidence for the role of the candidate genes in the pathological processes associated with COPD. This review describes the genetic predisposition of COPD. The current progress and future visions of genetic predisposition of COPD are further addressed.

\section{1) Background and Risk Factors of Develop- ment of COOD}

Chronic tobacco smoking is the major risk factor for the development of COPD, but only a relatively small propor- tion of smokers actually develop airway obstruction. Although there is a dose-response relationship between FEV1 and the extent of cigarette smoking, smoking history accounts for only approximately $15 \%$ of the variation in lung function. That is why the genetic predisposition of COPD may exist in smokers. Although cigarette smoking is the most important risk factor for the development of COPD, allergic airway inflammation, long-standing asthma, air pollutants, and diesel exhaust particles may also cause irreversible airflow limitation such as COPD. Environmental pollution, age, and airway hyperreactivity are also the risk factors. Destruction of the lung parenchyma leads to the loss of alveolar attachments to the small airways and decreases lung elastic recoil (Fig. 1).

\section{2) Candidate Gene-Association Studies for the Development of COPD}

\section{a) The genes related to the protease-antiprotease imbalances}

There are two major hypotheses on the cause of COPD and emphysema, such as the protease-antiprotease hypothesis and the oxidant-antioxidant hypothesis $(5,6)$. It is well known that the $\mathrm{Z}$ alpha (1) - antitrypsin homozygote is predisposed to developing early onset basal, panacinar emphy- 


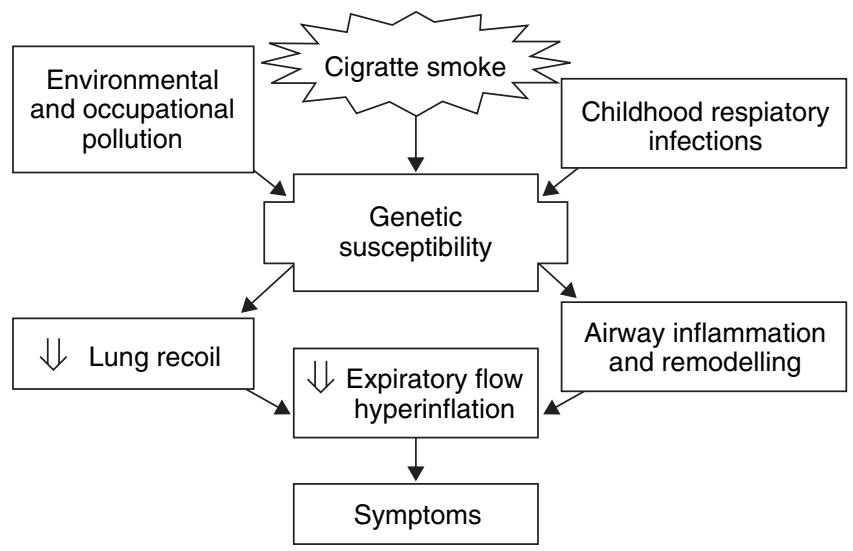

Figure 1. The risk factors for the development of COPD.

sema (7). In patients with the secretory defect of alpha (1)antitrypsin, the lung tissue is under uncontrolled proteolytic attack from neutrophil elastase, culminating in alveolar destruction (8-12). The mouse metalloelastase knock-out studies implicate this enzyme as a key mediator in the pathology associated with cigarette smoke-induced emphysema (13, 14). There is also associative evidence from human genetic and animal studies suggesting a pathological link with other MMPs. The polymorphism of alpha-1-antichymotrypsin (AACT) and tissue inhibitor of metalloproteinases-2 (TIMP2) gene polymorphisms may be associated with individual susceptibility to the development of COPD. The AACT/Ala15 genotype may be less protective against smoking injury.

\section{b) The genes related to the oxidant-antioxidant im- balance}

Oxidative stress is believed to play an important role in the pathogenesis of smoking-induced COPD. The second hypothesis is the oxidant-antioxidant theory, which proposes that oxidant stress and reactive oxygen species (ROS), resulting from an oxidant/antioxidant imbalance, have important consequences for the pathogenesis of COPD. These include oxidative inactivation of antiproteinases, alveolar epithelial injury, increased sequestration of neutrophils in the pulmonary microvasculature, and gene expression of proinflammatory mediators. Several studies have provided supportive evidence of a role for reactive oxygen species (ROS) released from circulating neutrophils and the development of airflow limitation. Thus, the presence of oxidative stress may have important consequences for the pathogenesis of COPD. Number of studies have been done on the identification of genes that predispose to the development of COPD.

Heme oxygenase-1 (HO-1) plays a protective role as an antioxidant in the lung. The length of the (GT)n repeat in the 5'-flanking region of human HO-1 gene polymorphism is associated with susceptibility to COPD (15). The polymorphisms of antioxidant genes glutathione S-transferase M1 (GSTM1) and GSTP1 are reported to be associated with susceptibility to an accelerated decline of lung function in smokers $(16,17)$.

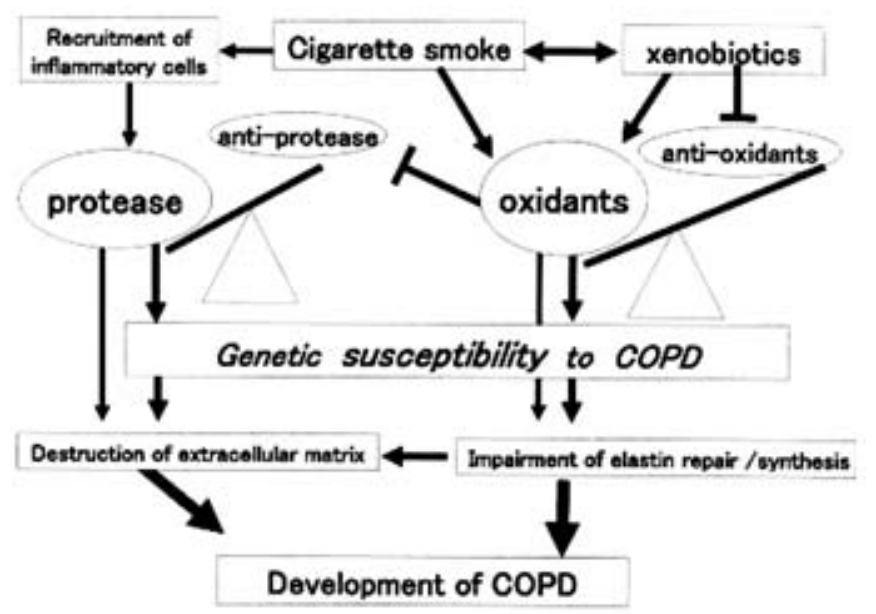

Teramoto $S$ et al. Xenobiotic enzymes and genetics of COPD. Chest 2005 ; 127 : 408-409

Figure 2. Hypothesis of genetic susceptibility to COPD (6).

\section{c) Xenobiotic enzymes and genetics of COPD}

Each puff of a cigarette contains $10^{17}$ free radicals and about 4000 substrates including carcinogenic agents and other possible causative agents of COPD such as volatile aldehydes and hydrogen cyanide. Thus, defects in the detoxification of these reactive species may predispose smokers to airflow obstruction and emphysema. It has been suggested that genetic polymorphisms of cytochrome P450, microsomal epoxide hydrolase (mEPHX) are associated with emphysema or COPD (18-20). The genetic polymorphism of exon 5 of smokers with glutathione S-transferase P1 (GSTP 1) is associated with the development of COPD in smokers (3). There is growing evidence for the role of xenobiotics and antioxidant imbalance in the pathogenesis of airflow obstruction, which is supported by association studies between COPD and variants in epoxide hydrolase and GSTs that detoxify free radicals and other tobacco products (10-14).

\section{d) Other genes associated with the genetic predis- position to COOD}

Because airway obstruction is due to both loss of lung elastic recoil and inflammatory narrowing of peripheral airways, genetic polymorphisms that affect either process could be involved. It has been suggested that genetic polymorphisms of tumour necrosis factor- $\alpha$, interleukin-13 (IL-13) gene promoter, and Vitamin D binding protein gene are associated with emphysema or COPD (21-23).

\section{3) The Pathologic Relationship between Respi- ratory Illness in Childhood and Chronic Air- Flow Obstruction in Adulthood. -Adenoviral Latent Infection Thytpothesis-}

It has been suggested that respiratory illness in childhood might cause chronic air-flow obstruction in adulthood. Hogg 
JC and colleagues have suggested an association between latent adenoviral infection with expression of the adenoviral $\mathrm{E}$ $1 \mathrm{~A}$ gene and COPD $(24,25)$. The present study focuses on how the adenoviral E1A gene could alter expression of growth factors by human bronchial epithelial (HBE) cells. The data show that connective tissue growth factor (CTGF) and transforming growth factor (TGF)-beta $1 \mathrm{mRNA}$ and protein expression were upregulated in E1A-positive HBE cells. The latent infection of epithelial cells by adenovirus $\mathrm{E}$ $1 \mathrm{~A}$ could contribute to airway remodeling in COPD by the viral E1A gene, inducing TGF-beta 1 and CTGF expression and shifting cells to a more mesenchymal phenotype.

\section{Conclusion and Implication}

Chronic obstructive pulmonary disease (COPD) is the collective term describing two separate chronic lung disease diseases: emphysema and chronic bronchitis. Results of many studies have suggested that the genetic susceptibility to COPD is dependent on the action of several gene polymorphisms operating in concert. Polymorphisms in an individual gene may impart only a small relative risk of COPD, and it is likely that the cumulative effect of many polymorphisms will be important in its pathogenesis. Before these associations are generally accepted, they must be subjected to scrutiny with further association studies in terms of ethnicity and COPD phenotypes.

Acknowledgements: This work was supported by a grant from Mitsui Life Social Welfare Foundation.

\section{References}

1. Murray CJL, Lopez AD. Evidence-Based Health Policy-Lessons from the Global Burden of Disease Study. Science 274: 740-743, 1996.

2. Teramoto S, Yamamoto H, Yamaguchi Y, Matsuse T, Ouchi Y. Global burden of COPD in Japan and Asia. Lancet 362: 17641765,2003

3. Sandford AJ, Weir TD, Pare PD. Genetic risk factors for chronic obstructive pulmonary disease. Eur Respir J 10: 1380-1391, 1997.

4. Pauwels RA, Rabe KF. Burden and clinical features of chronic obstructive pulmonary disease (COPD). Lancet 364: 613-620, 2004.

5. Molfino NA. Gentics of COPD. Chest 125: 1929-1940, 2004.

6. Teramoto $\mathrm{S}$, Ishii $\mathrm{T}$, Yamamoto $\mathrm{H}$, et al. Xenobiotic enzymes and genetics of COPD. Chest 127: 408-409, 2005.

7. Falk GA, Briscoe WA. Alpha-1-antitrypsin deficiency in chronic obstructive pulmonary disease. Ann Intern Med 72: 427-429, 1970.

8. Ishii $\mathrm{T}$, Matsuse $\mathrm{T}$, Teramoto $\mathrm{S}$, et al. Association between alpha1-antichymotrypsin polymorphism and susceptibility to chronic obstructive pulmonary disease. Eur J Clin Invest 30: 543-548, 2000.

9. Joos L, He JQ, Shepherdson MB, et al. Therole ofmatrix metalloproteinase polymorphisms in the rate of decline in lung function. Hum Mol Genet 11: 569-576, 2002.

10. Sandford AJ, Chagani T, Weir TD, et al. Susceptibility genes for rapid decline of lung function in the Lung Health Study. Am J Respir Crit Care Med 163: 469-473, 2001.

11. Hirano K, Sakamoto T, Uchida $Y$, et al. Tissue inhibitor of metalloproteinases-2 gene polymorphisms in chronic obstructive pulmonary disease. Eur Respir J 18: 748-752, 2001.

12. Minematsu N, Nakamura $H$, Tateno $H$. Genetic polymorphism in matrix metalloproteinase-9 and pulmonary emphysema. Biochem Biophys Res Commun 289: 116-119, 2001.

13. Hautamaki RD, Kobayashi DK, Senior RM, Shapiro SD. Requirement for macrophage elastase for cigarette smoke-induced emphysema in mice. Science 277: 2002-2004, 1997.

14. Foronjy RF, Okada Y, Cole R, D'Armiento J. Progressive adultonset emphysema in transgenic mice expressing human MMP-1 in the lung. Am J Physiol 284: L727-L737, 2003.

15. Yamada N, Yamaya M, Okinaga S, et al. Microsatellite polymorphism in the heme oxygenase-1 gene promoter is associated with susceptibility to emphysema. Am J Hum Genet 66: 187-195, 2000.

16. He JQ, Ruan J, Connett JE, et al. Antioxidant gene polymorphisms and susceptibility to a rapid decline in lung function in smokers. Am J Respir Crit Care Med 166: 323-328, 2002.

17. Ishii $T$, Matsuse $T$, Teramoto $S$, et al. Glutathione S-transferase P1 (GSTP1) polymorphism in patients with chronic obstructive pulmonary disease. Thorax 54: 693-696, 1999.

18. Smith CA, Harrison DJ. Association between polymorphism in gene for microsomal epoxide hydrolase and susceptibility to emphysema. Lancet 350: 630-633, 1997.

19. Koyama H, Geddes DM Genes. oxidative stress, and the risk of chronic obstructive pulmonary disease. Thorax 53 (Suppl): S10-S 14, 1998.

20. Minematsu N, Nakamura H, Iwata M, et al. Association of CYP2 A6 deletion polymorphism with smoking habit and development of pulmonary emphysema. Thorax 58: 623-628, 2003.

21. Sakao S, Tatsumi K, Igari H, et al. Association of tumor necrosis factor $\{$ alpha $\}$ gene promoter polymorphism with the presence of chronic obstructive pulmonary disease. Am J Respir Crit Care Med 163: 420-422, 2001.

22. van der Pouw Kraan TC, Kucukaycan M, Bakker AM, et al. Chronic obstructive pulmonary disease is associated with the 1055 IL-13 promoter polymorphism. Genes Immun 3: 436-439, 2003.

23. Schellenberg D, Pare P, Weir $\mathrm{T}$, et al. Vitamin D binding protein variants and therisk of COPD. Am J Respir Crit Care Med 157: 957-961, 1998.

24. Hogg JC. Role of latent viral infections in chronic obstructive pulmonary disease and asthma. Am J Respir Crit Care Med 164: S 71-S75, 2001.

25. Teramoto S, Kume H. The role of nuclear factor-kappa B activation in airway inflammation following adenovirus infection and COPD. Chest 119: 1294-1295, 2001.

(C) 2007 The Japanese Society of Internal Medicine http://www.naika.or.jp/imindex.html 